\title{
Invasive Nocardiosis: Disease Presentation, Diagnosis and Treatment - Old Questions, New Answers?
}

This article was published in the following Dove Press journal:

Infection and Drug Resistance

\begin{abstract}
Emmanuel Lafont ${ }^{1}, *$
Pierre-Louis Conan ${ }^{2, *}$

Véronica Rodriguez-Nava ${ }^{3}$

David Lebeaux ${ }^{4,5}$

'Department of Infectious Diseases and Tropical Medicine, Université de Paris, Necker-Enfants Malades University Hospital, Centre d'Infectiologie NeckerPasteur, Assistance Publique - Hôpitaux de Paris (AP-HP), Paris, France; ${ }^{2}$ Service de Maladies Infectieuses et Tropicales, Hôpital d'Instruction des Armées Bégin, Saint-Mandé, France; ${ }^{3}$ Research Group on Bacterial Opportunistic Pathogens and Environment UMR5557 Écologie Microbienne, French Observatory of Nocardiosis, Université de Lyon I, CNRS, VetAgro Sup, Lyon, France; ${ }^{4}$ Université de Paris, Paris 75006, France; ${ }^{5}$ Service de Microbiologie, Unité Mobile d'Infectiologie, Hôpital Européen Georges Pompidou, Assistance Publique Hôpitaux de Paris (AP-HP), Paris 750I5, France
\end{abstract}

*These authors contributed equally to this work

Correspondence: David Lebeaux Service de Microbiologie, Unité

Mobile d'Infectiologie, Hôpital Européen Georges Pompidou, Assistance Publique Hôpitaux de Paris (AP-HP), 20 Rue

Leblanc, Paris 75015 , France

Tel +33 I 56092969

Fax +33 I 56092446

Email david.lebeaux@aphp.fr

\begin{abstract}
Nocardia spp. is an environmental filamentous Gram-positive bacterium that may cause infections in humans and, despite recent progress, many challenges remain regarding the management of nocardiosis. This review aims at describing most recently published data regarding the diagnosis, treatment and follow-up of patients with invasive nocardiosis. As nocardiosis mainly affects patients with cell-mediated immunity defects, a comprehensive workup is mandatory in case of invasive nocardiosis occurring in "apparently healthy patients". Indeed, invasive nocardiosis might reveal an unknown primary immunodeficiency or the presence of anti-GM-CSF autoantibodies. Even if the diagnosis of nocardiosis mostly relies on direct examination and bacterial culture, a genus-specific PCR may be used for the detection of Nocardia, when directly performed on a clinical sample. Brain imaging should always be performed, even in the absence of neurological symptoms. Cotrimoxazole (trimethoprim/ sulfamethoxazole), linezolid, parenteral cephalosporins, carbapenems and amikacin may be used as initial antibiotics to treat nocardiosis. Cotrimoxazole or linezolid can be used as monotherapy in selected patients without brain involvement. Although treatment duration has historically been set to at least 6 months in the absence of central nervous system involvement, shorter durations ( $<120$ days) seem to be associated with a favourable outcome.
\end{abstract} Keywords: opportunistic infection, dissemination, anti-GM-CSF autoantibodies, brain imaging, molecular biology, antibiotic susceptibility testing, cotrimoxazole

\section{Introduction}

The first description of bacteria belonging to the genus Nocardia was made in 1888 by Edmond Nocard, a French veterinarian who was studying bovine farcy, a form of lymphadenitis that affects cattle. ${ }^{1}$ Later, Nocardia spp. were identified as important environmental bacteria, being universally present in soil, decaying vegetation and water. $^{2}$ In humans, Nocardia spp. are responsible for diseases ranging from cutaneous and subcutaneous infections (following local trauma) to invasive and potentially disseminated infections, especially in immunocompromised hosts. Although nocardiosis is rare in humans (with an incidence ranging from 0.33 to 0.87 for 100,000 inhabitants), thousands of studies have been published on this condition, most of them case-reports, small case-series or in vitro microbiological data. $^{3-5}$ This low-level evidence has been widely used in textbooks and to guide expert opinion, but more recent, higher quality clinical and microbiological data may provide a better evidence base to help physicians manage patients with nocardiosis. 
In this review, we will describe the most recently published data regarding the diagnosis, treatment and follow-up of patients with invasive nocardiosis. We will not cover the management of primary cutaneous nocardiosis.

\section{Disease Presentation}

Nocardial infection is acquired from environmental sources following local cutaneous trauma or inhalation. Primary cutaneous nocardiosis may affect immunocompetent patients after single or multiple bacterial inoculations through the skin. ${ }^{6}$ Because T-cell mediated immunity and lung macrophages play a key role in the local control of Nocardia, invasive nocardiosis mostly affect patients with cellular immunodeficiency (solid organ or hematopoietic stem cell transplant (HSCT) and patients receiving corticosteroids or immunosuppressive agents).$^{7-9}$ Patients with underlying chronic lung disease (mostly bronchiectasis and cystic fibrosis, and less frequently chronic obstructive pulmonary disease and emphysema) can also develop pulmonary nocardiosis, especially if they are using oral or inhaled corticosteroids. ${ }^{10-12}$ Although infection with human immunodeficiency virus (HIV) was historically considered a major risk factor for nocardiosis in the late 20th century, recent studies show that nocardiosis is rare in these patients, likely as a result of early use of highly active antiretroviral therapy. ${ }^{13}$ Diabetes mellitus, chronic kidney disease and liver cirrhosis are often cited as risk factors for invasive nocardiosis, but such associations have never been demonstrated. ${ }^{14,15}$ Finally, most of the patients with solid cancer or malignant hemopathy who develop invasive nocardiosis have received corticosteroids and/or antineoplastic chemotherapy and/or allogeneic HSCT prior to nocardiosis diagnosis, suggesting that cancer per se, is not a risk factor for nocardiosis. ${ }^{13,16}$

In recent European studies, solid organ transplantation appears to be the main underlying condition associated with invasive nocardiosis (present in $25-40 \%$ of cases). ${ }^{4,13}$ The incidence of nocardiosis was higher after heart or lung transplantation (1-3.5\%) compared to kidney or liver transplantation $(<1 \%)$, likely because of a higher level of druginduced immunosuppression and/or an impaired mucociliary clearance after lung transplantation. ${ }^{7}$ The following risk factors for invasive nocardiosis after solid organ transplantation have been identified: high trough levels of calcineurin inhibitor in the month before diagnosis, use of tacrolimus, high corticosteroid dose at the time of diagnosis, older patient age, and longer duration of stay in the intensive care unit after transplantation. ${ }^{14,15}$ Cytomegalovirus
(CMV) disease in the 6 months prior to diagnosis may also be a risk factor for development of invasive nocardiosis. ${ }^{14,15}$

Most case series of patients with nocardiosis have reported that $0 \%$ to $20 \%$ of cases occurred in "apparently healthy patients", likely reflecting inclusion bias and heterogeneity regarding the definition of a significant "underlying condition" (see earlier) ${ }^{4,13}$ Among these "apparently healthy patients", the presence of nocardiosis might reveal a previously unidentified primary immunodeficiency (PID). A retrospective study showed that among these cases of PID complicated by invasive nocardiosis, chronic granulomatous disease (CGD) was most common (43/49, 83.8\%). ${ }^{17}$ Even in this subpopulation, the incidence of nocardiosis was low, ranging from 0.0044 to 0.0057 cases/patient year. ${ }^{17}$ NonCGD PID (such as IL12RB1 deficiency or idiopathic CD4 lymphopenia) was rare, but often revealed by development of nocardiosis. More recently, anti-granulocyte-macrophage colony-stimulating factor (GM-CSF) autoantibodies, which reduce neutrophil and macrophage activation, phagocytosis, and bactericidal activity through the inhibition of GM-CSFinduced STAT5 phosphorylation, were identified in five out of seven patients with unexplained disseminated nocardiosis. ${ }^{18}$ These data support the need to perform a comprehensive workup if invasive nocardiosis is diagnosed in an "apparently healthy patient" (Figure 1).

Because inhalation is the primary route of entry for Nocardia spp., the most common site of infection is the lung $(62-86 \%))^{4,13,14}$ The radiological presentation of pulmonary nocardiosis is heterogeneous and non-specific: nodules (57-75\%; with cavitation in $23 \%$ to $40 \%$ of cases), lung consolidation (20-40\%), and pleural effusion (26-28\%) are the most commonly reported presentations on chest computed tomography (CT) scan (Figure 2A-C). ${ }^{14,19}$

The central nervous system (CNS) is the second most frequently involved organ (2-26\%) (Figure 2D). ${ }^{4,13,14} \mathrm{~A}$ retrospective study of 89 patients with cerebral nocardiosis showed that the main radiological feature was ring-enhancing lesions (93\%), of which 50\% were multiple, $50 \%$ were surrounded by edema and causing mass effects, and $15 \%$ were multilobulated. ${ }^{20}$ Among a European cohort of solid organ transplant recipients with CNS nocardiosis, $43.3 \%$ had no neurological symptoms, highlighting the importance of performing brain imaging on all patients with demonstrated or suspected invasive nocardiosis. ${ }^{14}$

About $8-31 \%$ of patients with invasive nocardiosis have skin involvement, ${ }^{4,13,14}$ which may present as isolated or multiple pustules, nodules or deep-seated 


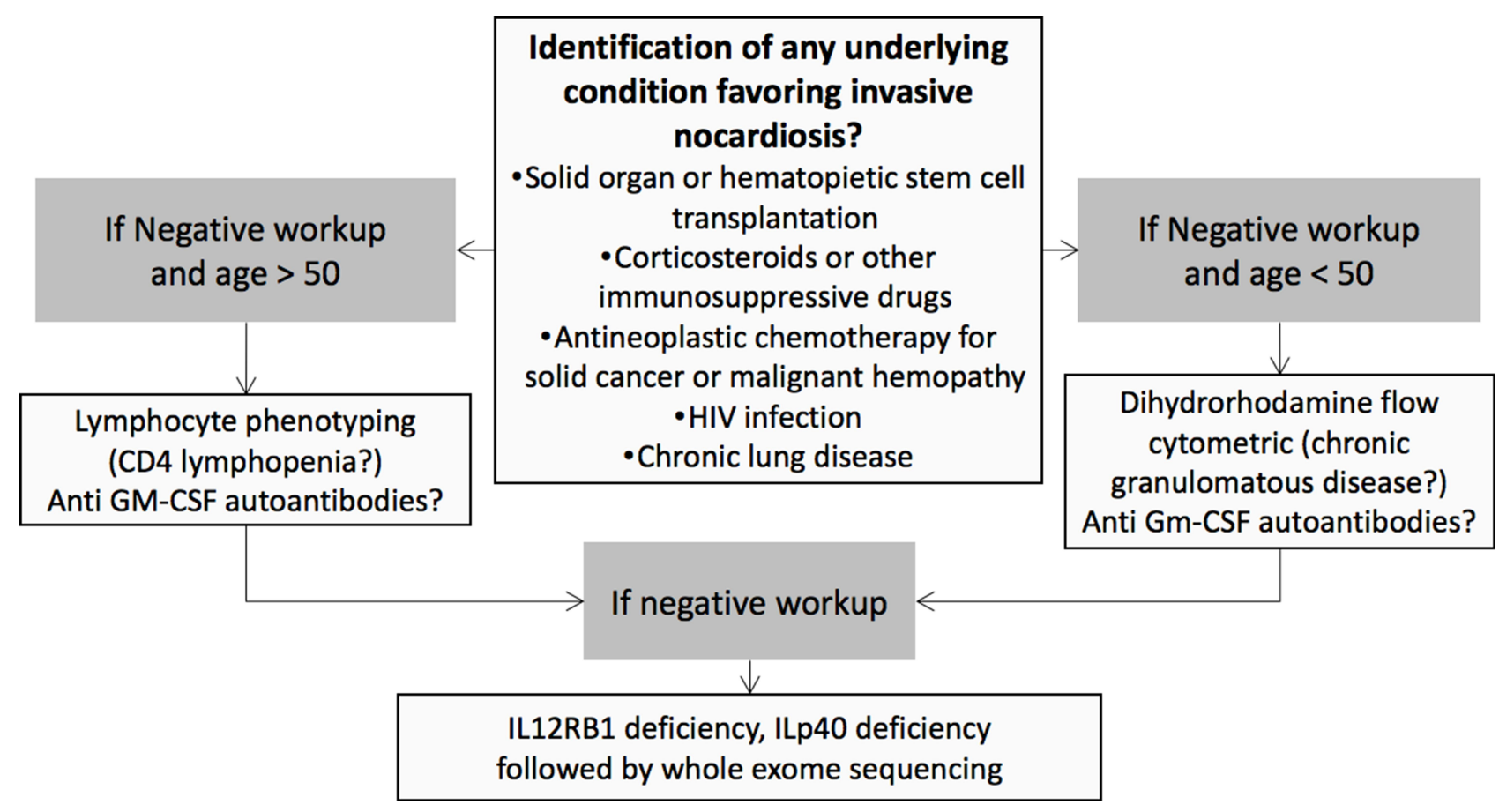

Figure I Workflow for identification of underlying disease favoring invasive nocardiosis. ${ }^{17}$

abscesses, possibly involving the muscles. Identification of such lesions by a complete clinical examination may prompt skin biopsy and lead to early and minimally invasive diagnosis.

Disseminated nocardiosis, defined as the involvement of at least two noncontiguous organs and/or demonstration of bloodstream infection, concerns $12 \%$ to $50 \%$ of patients with nocardial infection. ${ }^{4,13,14}$ Although the combination of lung, brain and cutaneous involvement is highly suggestive of nocardiosis, none of these organs are specific for nocardiosis. Virtually all organs can be involved in disseminated nocardiosis, leading to thyroid abscess, endophthalmitis, arthritis, liver or kidney abscess, and endocarditis, among others. ${ }^{2,21}$ In disseminated disease, 2-deoxy-2-[fluorine-18]fluoro-D-glucose $\left({ }^{18} \mathrm{~F}\right.$-FDG) positron emission tomography (PET)/CT can be used to assess the extent of invasive nocardiosis and to guide biopsy. ${ }^{22}$

As invasive nocardiosis mostly occurs among immunocompromised patients with no specific features, its diagnosis is challenging and requires a comprehensive microbiological workup, sampling all involved organs and eliminating possible differential diagnoses (see later). As the lungs are frequently involved in invasive nocardiosis, respiratory samples are a cornerstone for diagnosis. Bronchoalveolar lavage (BAL) samples can be used for bacteriological, mycobacteriological and mycological examinations. ${ }^{14,15}$ Lung biopsy may be required if BAL examination is negative, especially if there is a nodular lesion. ${ }^{17}$ If brain nocardiosis is suspected, obtaining a positive microbiological result using BAL or skin biopsy may prevent the need to perform an invasive procedure. If no diagnosis is reached despite the above-mentioned workup, stereotactic needle biopsy or craniotomy drainage should be performed if there is a brain abscess. ${ }^{20,23}$

\section{Microbiological Diagnosis}

The diagnosis of nocardiosis relies on close collaboration among physicians and clinical microbiologists. Direct examination, mostly performed by Gram-staining, can provide an early suspicion of nocardiosis (Figure 3A). Nocardia are weakly stained and appear as "dotted" or "striped" Gram-positive bacteria usually arranged as thin branched filaments fragmenting into bacillary or coccoid elements. ${ }^{24}$ Similar direct examination can also be seen with other Actinobacteria such as Streptomyces spp. or Actinomyces spp. ${ }^{25}$ Nocardia can be cultured on many different routine media, including blood or chocolate agar, buffered charcoal-yeast extract (BCYE) or Sabouraud agar. ${ }^{2,24}$ Cultures should be incubated for 14 to 21 days at $37^{\circ} \mathrm{C}$ in aerobic conditions enriched with $5 \%$ carbon dioxide in a humid atmosphere to avoid drying. Nocardia colonies are slightly raised in a dome shape, may 


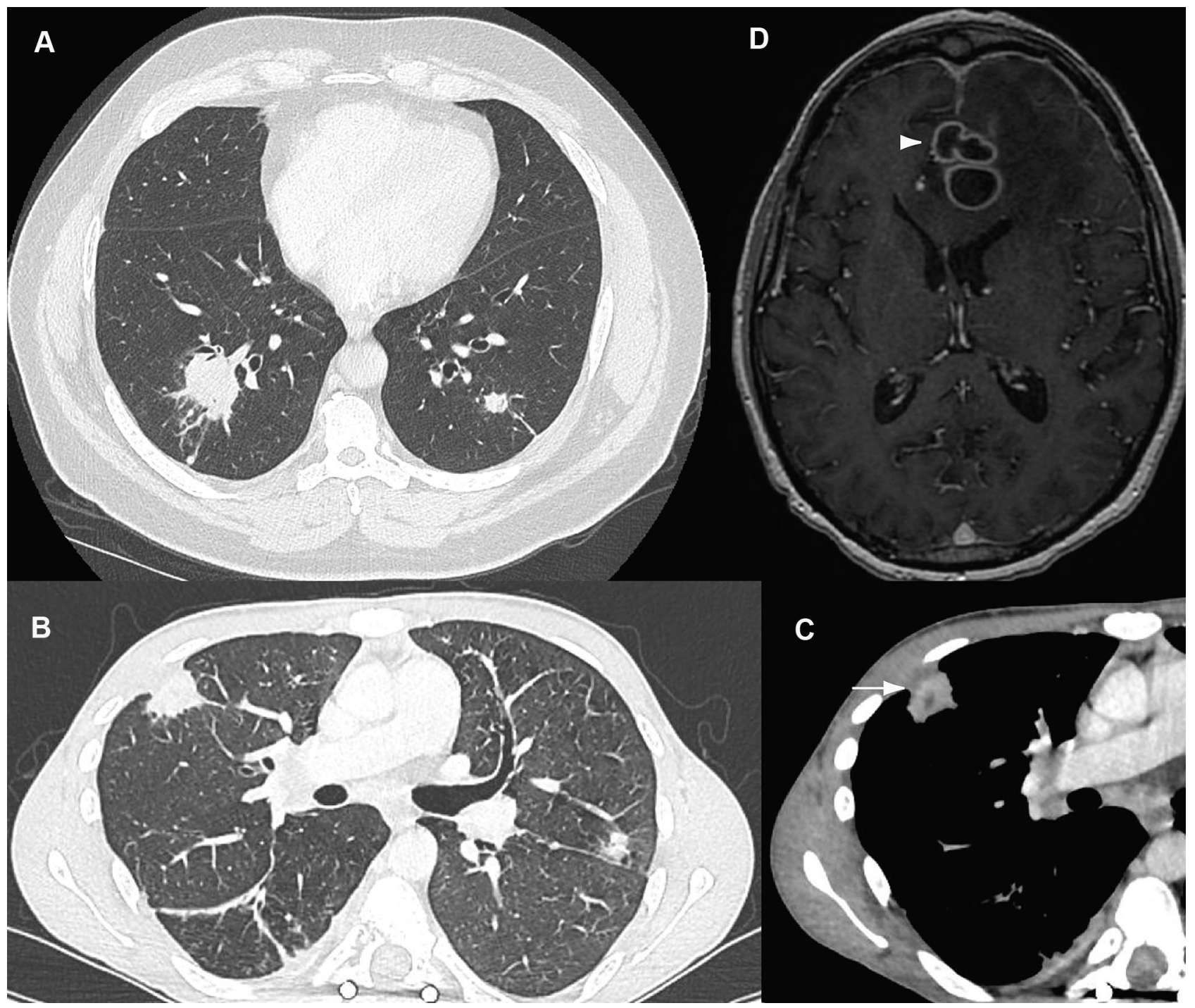

Figure 2 Radiographic findings in patients with invasive nocardiosis. (A) Chest CT-scan of a sixty-year-old patient with chronic lymphocytic leukemia treated with ibrutinib who developed Nocardia pneumonia. (B and C) Twenty-one-year-old patient with chronic granulomatous disease who developed Nocardia pulmonary abscess with local extension to the ribs (white arrow). (D) Brain MRI of a forty-six-year-old cardiac transplant patient who developed Nocardia brain cerebral abscess (white arrowhead): ringenhancing multilobulated lesion surrounded by edema causing a mass effect on the anterior ventricles. MRI, axial TI after gadolinium injection.

have a chalky aspect with a characteristic potting soil smell, and may be pigmented (beige-yellow, white, orange, or red-pink) (Figure 3B). ${ }^{26}$

In addition to cultures, molecular biology may be used to detect Nocardia, when directly performed on a clinical sample. This may allow earlier diagnosis or improved diagnosis if a patient has received antibiotics prior to collection of the clinical sample. A Nocardia genus-specific polymerase chain reaction (PCR)-based assay targeting a fragment of $\sim 600$ base pairs coding for the 16S rRNA gene has been developed as a diagnostic tool for clinical samples. ${ }^{27}$ This may be combined with a specific PCR designed to detect Nocardia farcinica, one of the most prevalent species. ${ }^{28}$ A prospective study performed in 68 immunocompromised patients identified a sensitivity of $88 \%$ and specificity of $74 \%$ for the Nocardia genus-specific PCR. ${ }^{29}$ This lack of specificity is mostly related to the possible detection of lung colonization, especially among patients with chronic bronchopulmonary disease. More recently, in a prospective study performed in 21 lung transplant patients, $24 \%(n=5)$ had a positive Nocardia PCR on BAL samples. ${ }^{30}$ None of these PCRpositive patients were diagnosed with nocardiosis after a median follow-up of 21 months. A positive Nocardia PCR on a respiratory sample should therefore be interpreted cautiously as it may just be an indication of lung colonization and not of infection. ${ }^{2}$ 


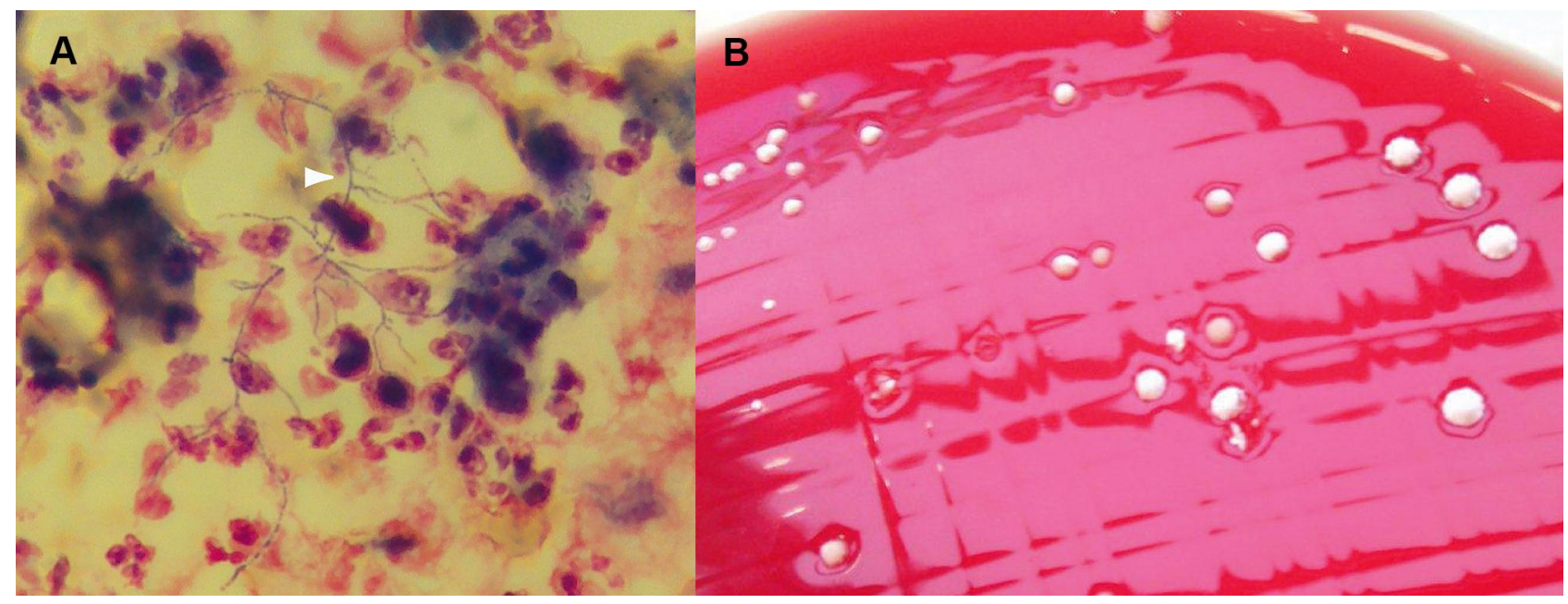

Figure 3 Microbiological diagnosis of nocardiosis. (A) Direct examination of a bronchoalveolar lavage (BAL) after Gram staining revealing filamentous Gram-positive bacteria (white arrowhead). (B) Positive culture of the same BAL on blood agar plate.

Once a Nocardia-like isolate has been identified by culture, the use of biochemical tests for genus or species identification should be abandoned, because of their lack of sensitivity and specificity. ${ }^{31}$ Identification of Nocardia at the species level should rely on molecular biology, ie, the amplification and sequencing of at least one gene among rrs (encoding 16S rRNA), hsp65, sodA or secA1. ${ }^{32-35}$ For clinical purposes, the decision to rely on a single gene requires $99.6 \%$ sequence similarity with a type strain of a single species; otherwise, another gene should be sequenced. ${ }^{3}$ For research purposes, phylogenetic analysis of concatenated sequences of several housekeeping genes may be required, such as MLSA (Multilocus Sequence Analysis), to enhance discrimination among species or within species complexes. ${ }^{36}$ In addition to singlegene PCR approaches, high-throughput sequencing (HTS) can be used to obtain the entire genome of a microorganism in order to determine the relationship between isolates or to study the evolution within a single species. For Nocardia genus, HTS has been used to study phylogeny among species and to explore the genetic diversity inside phylogroups of the same species. ${ }^{37,38}$

Since the advent of Matrix-Assisted Laser Desorption Ionization-Time of Flight Mass Spectrometry (MALDITOF MS) in clinical microbiology laboratories, MS identification of Nocardia at the species level has been met with several difficulties. The main limitation is the large number of Nocardia species (more than 100 so far), only a limited number of which were included in initial databases. ${ }^{39}$ However, recent studies using improved databases showed that MALDI-TOF MS correctly identified the species in $100 \%$ of cases for $N$. farcinica and between $94 \%$ and $100 \%$ for $N$. cyriacigeorgica ${ }^{40-42}$ A preliminary step of protein extraction (with glass beads and ethanol, followed by formic acid) and repeated spotting of different extracts is frequently required to increase the likelihood of identification. ${ }^{43,44}$ For other clinically frequent species, such as $N$. nova and $N$. abscessus, the ability of MALDITOF MS to discriminate phylogenetically close species inside their respective complexes is limited. This limitation applies to the $N$. nova (including $N$. nova sensu stricto, N. aobensis, N. africana, N. cerradoensis, N. elegans, N. kruczakiae, N. mikamii and N. veterana) and $N$. abscessus (including $N$. abscessus sensu stricto, N. arthritidis, N. asiatica, N. beijingensis and $N$. pneumoniae) complexes. When identified by MALDI-TOF MS, these species should therefore be referred to as " $N$. nova complex" or " $N$. abscessus complex" and/or should be analyzed using molecular biology (see earlier) ${ }^{45}$ For rare species, MALDI-TOF MS should be used cautiously for species identification because a significant proportion of cases are misidentified and molecular biology-based identification should be performed for cases of "no identification" or low score results. ${ }^{42}$ Despite its limitations, MALDI-TOF MS enables rapid identification, at least at the genus level, and at the species level for the most frequent clinical species. As each Nocardia species is associated with a specific antibiotic susceptibility pattern, it is important for clinical microbiology laboratories to be able to provide reliable species identification, to guide the choice of initial antimicrobial therapy (see later). 
In vitro determination of the antibiotic susceptibility of a Nocardia isolate may also be used to guide antimicrobial therapy, but has several technical difficulties, including those related to the choice of in vitro method, and difficulties related to the inoculum preparation, and reading and interpretation of the results. The only available international guidelines (clinical and laboratory standards institute, CLSI) recommend performing broth microdilution (BMD) for antibiotic susceptibility testing of Nocardia. ${ }^{46}$ However, no clinical study has demonstrated that clinical outcomes can be predicted by results obtained using BMD. Furthermore, BMD may lack inter-laboratory reproducibility and may give false-resistant results for ceftriaxone and imipenem, which therefore need to be confirmed using another method. ${ }^{46,47}$ Other methods can be used, such as determination of the minimum inhibitory concentration (MIC) using E-test strips or antibiotic disk diffusion on agar plates. ${ }^{3,48}$ Nocardia antibiotic susceptibility testing is complex and in vitro data and expected antibiotic susceptibilities based on species identification need to be compared (Table 1). The most striking differences between Nocardia species are their different susceptibility profiles to B-lactam antibiotics. N. cyriacigeorgica is frequently susceptible to cefotaxime or ceftriaxone, whereas $N$. farcinica is almost always resistant to these drugs. ${ }^{3,48,49}$ Imipenem appears to be the carbapenem that most frequently has in vitro activity against most of the isolates belonging to the $N$. nova complex, $N$. cyriacigeorgica and $N$. farcinica species (Table 1). Of note, no B-lactam antibiotic should be used as monotherapy for initial antibiotic therapy if species identification or antibiotic susceptibility testing are not available.

\section{Treatment}

Antibiotic therapy is usually initiated after nocardiosis has been microbiologically confirmed. However, if there is life-threatening disease and nocardiosis is suspected based on clinical and/or radiological data (see earlier), then antibiotics should be started after microbiological samples have been performed. ${ }^{2}$ In this case, empiric antibiotic therapy must be chosen that will reach all likely infected sites and be active against all Nocardia species; the patient's kidney function and other medications (including immunosuppressive therapies) should also be taken into account. ${ }^{7}$ Five classes of antibiotics are often used as initial therapy, based on their broad spectrum: carbapenems (imipenem and meropenem), cotrimoxazole (the combination of trimethoprim and sulfamethoxazole), linezolid, amikacin, and parenteral cephalosporins (ceftriaxone and cefotaxime). Cotrimoxazole, linezolid, and amikacin are active against $>95 \%$ of Nocardia isolates (Table 2). The frequently unpredictable antibiotic susceptibility profiles, demonstration of antibiotic synergy in animal models, and high mortality rates have historically supported the use of a combination of two bactericidal antibiotics (such as imipenem, cephalosporins, and/or amikacin). ${ }^{50-52}$ However, no controlled trial has ever studied the benefits of a multi-drug regimen and a recent retrospective study showed that use of a multi-drug regimen was not associated with improved survival in post-solid organ transplant nocardiosis. ${ }^{53}$ In this context, cotrimoxazole monotherapy appears to be an attractive option because it has good oral availability and achieves high tissue concentrations, including in the CNS. ${ }^{54}$ In addition, cotrimoxazole is active against all Nocardia species: in a North-American study of 552 clinical Nocardia isolates, only $0.5 \%$ of them were resistant to cotrimoxazole. ${ }^{55}$ In a recent retrospective study including 55 patients with Nocardia pneumonia (only 2 with CNS involvement), survival rates were comparable when cotrimoxazole was used either as monotherapy or as part of a multi-drug regimen. ${ }^{56}$ In a European retrospective study, 31 solid organ transplant patients with invasive nocardiosis were treated with cotrimoxazole monotherapy. Adverse events led to treatment discontinuation in up to $30 \%$ of patients, mostly for hematological toxicity and increase in serum creatinine. ${ }^{57}$ However, clinical cure without relapse occurred in $95 \%(19 / 20)$ of the patients who received a complete antibiotic course, including $8(42 \%)$ with disseminated infection and $2(11 \%)$ with brain abscess.

Because of its broad activity against all Nocardia species and excellent diffusion to all body sites, linezolid can be proposed in the treatment of nocardiosis as part of a multi-drug regimen or as monotherapy. ${ }^{58,59}$ Of note, the combination of linezolid and amikacin should be avoided due to the frequent antagonism of these two agents described in vitro. ${ }^{60}$

Cotrimoxazole or linezolid can therefore be used as monotherapy in patients with skin or non-severe pulmonary disease (Table 3); because of their excellent bioavailability, intravenous treatment is not mandatory. ${ }^{61}$ However, in life-threatening pneumonia or with CNS involvement, a multi-drug regimen is preferable, with a combination of two or three drugs (Table 3). ${ }^{62}$ 


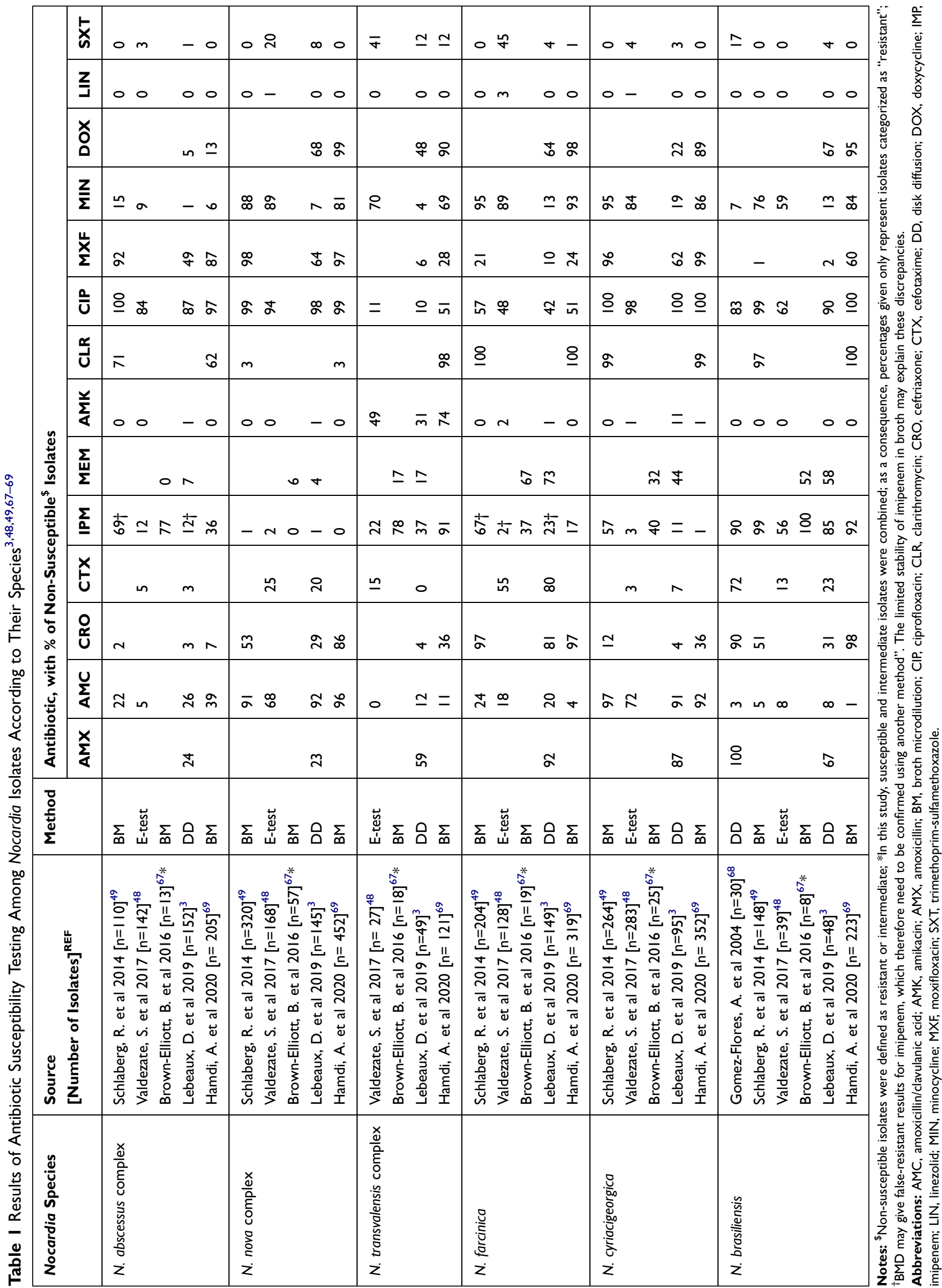


Table 2 Main Characteristics of Antibiotics That Can Be Used Before Obtaining the Results of Antibiotic Susceptibility Testing, ie, for the Initial Antibiotic Treatment ${ }^{2,62,70}$

\begin{tabular}{|c|c|c|c|c|c|c|}
\hline \multirow[t]{2}{*}{ Characteristics } & \multirow[t]{2}{*}{ Cotrimoxazole } & \multirow[t]{2}{*}{ Linezolid } & \multicolumn{2}{|c|}{$\begin{array}{l}\text { Parenteral } \\
\text { Cephalosporins }\end{array}$} & \multirow[t]{2}{*}{ Imipenem $^{\mathbf{a}}$} & \multirow[t]{2}{*}{ Amikacin } \\
\hline & & & Cefotaxime & Ceftriaxone & & \\
\hline Total daily dose ${ }^{b}$ & $10-20(15) \mathrm{mg}$ TMP/kg/d ${ }^{\mathrm{c}}$ & $1200 \mathrm{mg} / \mathrm{d}$ & $6-12 \mathrm{~g} / \mathrm{d}$ & $2 \mathrm{~g} / \mathrm{d}$ & $2-3 \mathrm{~g} / \mathrm{d}$ & $20-30 \mathrm{mg} / \mathrm{kg} / \mathrm{d}$ \\
\hline $\begin{array}{l}\text { Route of } \\
\text { administration }\end{array}$ & PO or IV & PO or IV & IV & IV & IV & IV \\
\hline $\begin{array}{l}\text { Number of daily } \\
\text { doses }\end{array}$ & 3 or 4 & 2 & 3 & I & 3 or 4 & 1 \\
\hline Oral bioavailability & $80 \%$ & $100 \%$ & NA & NA & NA & NA \\
\hline $\begin{array}{l}\text { Drug concentration } \\
\text { ratio CSF/C serum }\end{array}$ & $50 \%$ & $80 \%$ & $10-50 \%$ & $10 \%$ & $10 \%$ & $10 \%$ \\
\hline $\begin{array}{l}\text { Interference with } \\
\text { immunosuppressive } \\
\text { agents }\end{array}$ & $\begin{array}{l}\uparrow \text { Cyclosporine/ } \\
\text { tacrolimus-related } \\
\text { nephrotoxicity. } \\
\text { Contraindication with } \\
\text { methotrexate }^{c}\end{array}$ & & & & & $\begin{array}{l}\uparrow \text { Cyclosporine/ } \\
\text { tacrolimus- } \\
\text { related } \\
\text { nephrotoxicity }\end{array}$ \\
\hline $\begin{array}{l}\text { Main adverse } \\
\text { events }^{\mathrm{d}}\end{array}$ & $\begin{array}{l}\text { Myelosuppression, serum } \\
\text { creatinine increase }\end{array}$ & $\begin{array}{l}\text { Myelosuppression, } \\
\text { peripheral } \\
\text { neuropathy }\end{array}$ & & & Seizures & $\begin{array}{l}\text { Nephrotoxicity, } \\
\text { ototoxicity }\end{array}$ \\
\hline $\begin{array}{l}\text { Management/ } \\
\text { prevention of } \\
\text { adverse events }\end{array}$ & $\begin{array}{l}\text { - Consider "false" } \\
\text { nephrotoxicity before } \\
\text { stopping cotrimoxazole } \\
\text { - Adjunction of folinic acid } \\
\text { if progressive } \downarrow \text { of blood } \\
\text { cells } \\
\text { - Switch to another } \\
\text { antibiotic }\end{array}$ & $\begin{array}{l}\text { - Obtain blood } \\
\text { concentration } \\
\text { (trough target 2-6mg/ } \\
\text { L) } \pm \text { dose reduction. } \\
\text { - Possibility of } \\
\text { myelosuppression- } \\
\text { sparing antibiotic with } \\
\text { tedizolidf. } \\
\text { - Switch to another } \\
\text { antibiotic. }\end{array}$ & $\begin{array}{l}\text { - Obtain blooc } \\
\pm \text { dose reduct } \\
\text { - Switch to an }\end{array}$ & $\begin{array}{l}\text { concentration } \\
\text { on. } \\
\text { ther antibiotic }\end{array}$ & $\begin{array}{l}\text { - Consider } \\
\text { switch to } \\
\text { meropenem. }{ }^{\text {a }} \\
\text { - Switch to } \\
\text { another } \\
\text { antibiotic }\end{array}$ & $\begin{array}{l}\text { - Obtain } \\
\text { undetectable } \\
\text { amikacin level } \\
\text { before next } \\
\text { injection. } \\
\text { - Switch to } \\
\text { another } \\
\text { antibiotic }\end{array}$ \\
\hline
\end{tabular}

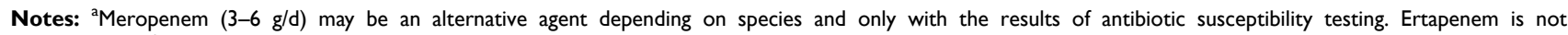
recommended; ${ }^{b}$ All these antibiotics must be adapted to renal function. Therapeutic drug monitoring may be required. $8 \mathrm{mg} / \mathrm{kg} / \mathrm{d}$ in case of primary cutaneous nocardiosis; 'Major drug interaction between methotrexate and cotrimoxazole, which increases the risk of methotrexate-related toxicity, like severe pancytopenia. Prophylactic dose of cotrimoxazole is possible with methotrexate; ${ }^{\mathrm{d}} \mathrm{All}$ these antibiotics may induce skin rashes, anaphylaxis, and digestive symptoms including Clostridioides difficile infections; ${ }^{\text {e}}$ Systematic increase in creatinine concentration can occur when taking trimethoprim/sulfamethoxazole due to its inhibitory effects on tubular creatinine secretion, with no modification of the measured GFR. A moderate $(\approx 20-30 \%)$ increase in creatinine concentration, with no other AE should not prompt SXT interruption but rather encourage close monitoring and possibly the use of non-creatinine-based equations (eg, cystatin $\mathrm{C}$ ) to assess renal function; ${ }^{\mathrm{f}}$ Tedizolid, a more recent agent from the oxazolidinone class of antibiotics, may be a therapeutic option as suggested by a recent case report.

Abbreviation: CSF, cerebrospinal fluid.

Although no study has assessed the impact of the duration of intravenous antibiotics on patient outcomes, intravenous antibiotic therapy is usually prescribed for at least 2-3 weeks for invasive nocardiosis without CNS involvement, and 3-6 weeks for CNS nocardiosis. For patients whose treatment is initiated intravenously, switching to an oral regimen is possible if all the following criteria are met: i) reliable isolate characterization, ii) clinical improvement, iii) strain susceptible to at least one drug with good oral bioavailability and penetration into the infected sites, iv) no concern regarding digestive absorption. ${ }^{7}$

The total recommended duration of antibiotic treatment for invasive nocardiosis without CNS involvement has historically been set at 6 months, based on a single retrospective study that included 34 patients treated with cotrimoxazole monotherapy (9 skin and 25 pulmonary nocardiosis). ${ }^{63}$ In this study, the authors showed that 3 out of 5 patients $(60 \%)$ who completed $\leq 3$ months of therapy relapsed within 4 
Table 3 Proposed Initial Treatment and Antibiotic Duration for Invasive Nocardiosis, Based on Clinical Presentation, Before Obtaining Species Identification and/or Antibiotic Susceptibility Testing

\begin{tabular}{|c|c|}
\hline $\begin{array}{l}\text { Clinical } \\
\text { Presentation }\end{array}$ & $\begin{array}{l}\text { Initial Antibiotic Treatment, Antibiotic } \\
\text { Duration }\end{array}$ \\
\hline Skin* & $\begin{array}{l}\text { Monotherapy: cotrimoxazole OR linezolid } \\
\text { Antibiotic duration: } 3 \text { months. Initial oral } \\
\text { treatment is possible. }\end{array}$ \\
\hline $\begin{array}{l}\text { Pulmonary, non- } \\
\text { severe* }\end{array}$ & $\begin{array}{l}\text { Monotherapy: cotrimoxazole OR linezolid } \\
\text { Antibiotic duration: } 4 \text { to } 6 \text { months. Initial oral } \\
\text { treatment is possible. }\end{array}$ \\
\hline $\begin{array}{l}\text { Pulmonary, } \\
\text { severe* }\end{array}$ & $\begin{array}{l}\text { Multi-drug regimen: } 2 \text { drugs among the } 5 \text { first- } \\
\text { line agents. Possible combinations include: } \\
\text { - [Imipenem OR cefotaxime OR ceftriaxone] + } \\
\text { [amikacin OR cotrimoxazole OR linezolid] } \\
\text { Antibiotic duration: } 4 \text { to } 6 \text { months. } 2-3 \text { weeks of } \\
\text { intravenous therapy. }\end{array}$ \\
\hline $\begin{array}{l}\text { Central nervous } \\
\text { system* }\end{array}$ & $\begin{array}{l}\text { Multi-drug regimen: } 2 \text { to } 3 \text { drugs among the first- } \\
\text { line agents. Possible combinations include: } \\
\text { - [Imipenem OR cefotaxime OR ceftriaxone] + } \\
\text { amikacin + cotrimoxazole } \\
\text { - [Imipenem OR cefotaxime OR ceftriaxone] + } \\
\text { [cotrimoxazole OR linezolid] } \\
\text { Antibiotic duration: } 12 \text { months. } 3-6 \text { weeks of } \\
\text { intravenous therapy. }\end{array}$ \\
\hline
\end{tabular}

Notes: Associated measures: In case of abscess, surgical treatment or radiologic aspiration should be considered. *Based on animal studies and numerous case series; No controlled trials available.

weeks. Conversely, among the 10 patients who completed 4 to 6 months of therapy, only $1(10 \%)$ relapsed and this relapse was due to antibiotic resistance. ${ }^{63}$ However, antibiotic doses in this study were in the range of 5-10 mg of trimethoprim (TMP)/kg, which is less than currently proposed dosages (usually $15 \mathrm{mg}$ of TMP/kg per day (see Table 2)). 7,62 More recent data with other antibiotic regimens or higher cotrimoxazole daily doses suggest that the antibiotic duration could be shortened. Tripodi and coworkers described 12 patients with pulmonary nocardiosis after heart transplantation who initially received bactericidal antibiotics (mostly imipenem/amikacin combination) followed by oral drugs for a total of 3 to 4 months of treatment: there were no relapses. ${ }^{60}$ More recently, a subset of 17 patients, from 117 with post-solid organ transplant nocardiosis, who received antibiotic treatment for less than 120 days was described; ${ }^{53}$ although the median antibiotic duration was 56 [24-120] days, only one patient relapsed. ${ }^{53}$ In all these cases, patients received at least 2 weeks of intravenous bactericidal antibiotics. These data suggest that in patients with pulmonary or cutaneous nocardiosis initially treated with bactericidal antibiotics, and who show clinical improvement, the duration of treatment can be reduced to 4 months, especially if the patient experiences antibiotic-related adverse effects.

If there is CNS involvement, treatment is usually maintained for 12 months, although, again, no studies have been conducted to assess shorter durations (Table 3).

Apart from antibiotic therapy, surgical treatment should be considered for deep abscesses, if there is no microbiological diagnosis or if antibiotic treatment alone is not effective, especially if there is CNS involvement. ${ }^{20}$

After completion of antibiotic therapy, secondary prophylaxis may be considered, especially if there is an ongoing immunosuppressive condition. No randomized study has shown a benefit of cotrimoxazole prophylaxis in this setting. Because low-dose cotrimoxazole does not prevent nocardiosis among solid organ transplant recipients, higher doses should be used for secondary prophylaxis, as shown in patients with CGD (eg, 160/800 mg of TMP-SMX daily). ${ }^{7,14,15,17}$

\section{Follow-Up and Prognosis}

No data have been published to describe how quickly a patient with nocardiosis should improve after initiating antibiotic treatment; the following proposals are therefore based on expert opinion. Apyrexia is usually achieved after a few days of antibiotic treatment and skin lesions improve within weeks. Follow-up imaging focusing on the body site that was initially infected is mandatory to study the patient's response to treatment. During follow-up, clinical or radiological worsening should encourage consideration of several possibilities. First, treatment failure may be caused by antibiotic under-dosing, poor adherence to treatment, interaction with other treatments, or poor distribution of antibiotics to infected sites. Therapeutic drug monitoring can be performed to rule out these hypotheses. Second, treatment failure may occur if the Nocardia isolate is resistant to the prescribed antibiotics, again highlighting the importance of continuous collaboration between physicians and clinical microbiologists. The presence of co-infections, defined as additional microbial pathogens identified at the time of nocardiosis diagnosis, should also be investigated if the patient's condition worsens despite the use of effective antibiotics. The likely types of co-infection will depend on the geographical area and a patient's underlying conditions. For example, among 117 post-solid organ transplant patients with 
nocardiosis diagnosed in Europe, co-infections were identified in 40 patients (34\%), most of them caused by fungi or cytomegalovirus. ${ }^{53}$ In a retrospective study of 70 patients from Thailand, all 8 co-infections were identified among HIV-infected patients and were caused by Mycobacterium tuberculosis, Cryptococcus neoformans or Histoplasma capsulatum. ${ }^{64}$ Fungal co-infections were also demonstrated among 3/45 (6.7\%) patients with primary immunodeficiency. ${ }^{17}$ Finally, if none of the abovementioned reasons is identified, a paradoxical reaction should be considered. However, this event seems to be extremely rare: a single case-report has been published to date, of a paradoxical response in cerebral nocardiosis occurring in a renal transplant recipient. ${ }^{65}$

If there is lung involvement, a repeat chest CT-scan should be performed after 2 to 6 weeks. An early CT-scan ( 2 weeks) may be appropriate if the patient's clinical status does not improve in order to identify a local cause of unfavorable outcome (pleural effusion, lung abscess) or to demonstrate an increase in nodule size, thus justifying drainage of any collection or a lung biopsy (to investigate the presence of co-infection and/or differential diagnosis). If the patient's clinical condition is improving, early chest CTscan is unlikely to provide useful information and should be performed later, after $\sim 6$ weeks of antibiotic treatment.

For nocardial brain abscesses, radiological improvement is rarely observed before 4 to 6 weeks of antibiotic treatment. Earlier brain imaging is therefore only justified if there is a suspicion of local worsening, which may prompt stereotactic needle biopsy or craniotomy drainage for abscess evacuation and/or identification of any additional pathogens.

As for invasive fungal infection, one may expect PET/ CT to be helpful to assess response to antibiotic treatment and eventually guide its discontinuation, but further studies are required to address this question. ${ }^{66}$

Recent data enable the prognosis of invasive nocardiosis to be more accurately defined. In two case-control studies of post-solid organ transplantation nocardiosis, 6month and 12-month mortality were $14 \%$ and $16.2 \%$, respectively. ${ }^{15,53}$ In the more recent study, the authors identified the following factors as being associated with 12-month mortality: history of tumor or invasive fungal infection and donor age. ${ }^{53}$ Conversely, acute rejection in the year before nocardiosis was associated with improved survival. Of note, dissemination or CNS involvement were not associated with higher mortality in multivariable analysis. Among patients with CGD (median age 19 (1-53) years), 12-month mortality appears to be lower: $4.3 \%$ (2/
49). ${ }^{17}$ Strikingly, a higher 12 -month mortality rate of $38.2 \%$ was described in a recent retrospective Spanish study describing 55 cases of Nocardia pneumonia (only 2 with CNS involvement). ${ }^{56}$ In multivariable analysis, the single factor associated with mortality was systemic corticosteroids. Taken together, these data suggest that patient age and comorbidities have more influence on patient outcomes than the characteristics of the infection.

\section{Conclusion}

Recent clinical and microbiological data may help challenge historical attitudes towards the management of invasive nocardiosis. Invasive nocardiosis is an opportunistic infection, and the presence of cellular immunodeficiency should be investigated among "apparently healthy patients" with nocardial infection. In the near future, one can expect that whole genome sequencing will be routinely performed on the patient side to identify PID or to obtain complete microbial genomes in order to guide initial antibiotic treatment. ${ }^{18}$ F-FDG PET/CT imaging may also be considered to enable antibiotic durations to be personalized, thus reducing the risk of antibiotic-related adverse effects. Finally, the use of immunomonitoring (such as the validation of a phenotypic test measuring the level of drug-induced immunosuppression) may help to individually assess the risk of opportunistic infections among transplanted patients. However, the rarity of invasive nocardiosis likely precludes the possibility of performing any large scale randomized studies to address questions related to optimal initial antibiotic treatment and overall treatment duration.

\section{Acknowledgments}

We thank K Pickett for her editorial assistance.

EL and PLC contributed equally to this paper: co-first authors.

\section{Disclosure}

The authors report no conflicts of interest for this work.

\section{References}

1. Nocard E. Note sur la maladie des boeufs de la Gouadeloupe connue sous le nom de farcin. Ann Inst Pasteur. 1888;2:293-302.

2. Brown-Elliott BA, Brown JM, Conville PS, Wallace RJ. Clinical and laboratory features of the Nocardia spp. based on current molecular taxonomy. Clin Microbiol Rev. 2006;19(2):259-282. doi:10.1128/ CMR.19.2.259-282.2006

3. Lebeaux D, Bergeron E, Berthet J, et al. Antibiotic susceptibility testing and species identification of Nocardia isolates: a retrospective analysis of data from a French expert laboratory, 2010-2015. Clin Microbiol Infect. 2019;25(4):489-495. doi:10.1016/j.cmi.2018.06.013 
4. Minero MV, Marin M, Cercenado E, Rabadan PM, Bouza E, Munoz P. Nocardiosis at the turn of the century. Medicine (Baltimore). 2009;88(4):250-261. doi:10.1097/MD.0b013e3181afa1c8

5. Tremblay J, Thibert L, Alarie I, Valiquette L, Pepin J. Nocardiosis in Quebec, Canada, 1988-2008. Clin Microbiol Infect. 2011;17(5):690696. doi:10.1111/j.1469-0691.2010.03306.x

6. Welsh O, Vera-Cabrera L, Welsh E, Salinas MC. Actinomycetoma and advances in its treatment. Clin Dermatol. 2012;30(4):372-381. doi:10.1016/j.clindermatol.2011.06.027

7. Coussement J, Lebeaux D, Rouzaud C, Lortholary O. Nocardia infections in solid organ and hematopoietic stem cell transplant recipients. Curr Opin Infect Dis. 2017;30(6):545-551. doi:10.1097/ QCO.0000000000000404

8. Margalit I, Muhsen K, Ben Ari Y, et al. Nocardia colonization in contrast to nocardiosis: a comparison of patients' clinical characteristics. Eur J Clin Microbiol Infect Dis. 2020;39(4):759-763. doi:10.1007/s10096-019-03796-5

9. Beaman BL, Beaman L. Nocardia species: host-parasite relationships. Clin Microbiol Rev. 1994;7(2):213-264. doi:10.1128/ CMR.7.2.213

10. Fujita T, Ikari J, Watanabe A, Tatsumi K. Clinical characteristics of pulmonary nocardiosis in immunocompetent patients. $J$ Infect Chemother. 2016;22(11):738-743. doi:10.1016/j.jiac.2016.08.004

11. Rodriguez-Nava V, Durupt S, Chyderiotis S, et al. A French multicentric study and review of pulmonary Nocardia spp. in cystic fibrosis patients. Med Microbiol Immunol. 2015;204(4):493-504. doi:10.1007/s00430-014-0360-3

12. Woodworth MH, Saullo JL, Lantos PM, Cox GM, Stout JE. Increasing Nocardia incidence associated with bronchiectasis at a tertiary care center. Ann Am Thorac Soc. 2017;14(3):347-354. doi:10.1513/AnnalsATS.201611-907OC

13. Haussaire D, Fournier PE, Djiguiba K, et al. Nocardiosis in the south of France over a 10-years period, 2004-2014. Int J Infect Dis. 2017;57:13-20. doi:10.1016/j.ijid.2017.01.005

14. Coussement J, Lebeaux D, van Delden C, et al. Nocardia infection in solid organ transplant recipients: a multicenter European casecontrol study. Clin Infect Dis. 2016;63(3):338-345. doi:10.1093/cid/ ciw241

15. Peleg AY, Husain S, Qureshi ZA, et al. Risk factors, clinical characteristics, and outcome of Nocardia infection in organ transplant recipients: a matched case-control study. Clin Infect Dis. 2007;44 (10):1307-1314. doi:10.1086/514340

16. Wang HL, Seo YH, LaSala PR, Tarrand JJ, Han XY. Nocardiosis in 132 patients with cancer: microbiological and clinical analyses. Am J Clin Pathol. 2014;142(4):513-523. doi:10.1309/ AJCPW84AFTUWMHYU

17. Lafont E, Marciano BE, Mahlaoui N, et al. Nocardiosis associated with primary immunodeficiencies (Nocar-DIP): an international retrospective study and literature review. J Clin Immunol. 2020;40 (8):1144-1155. doi:10.1007/s10875-020-00866-8

18. Rosen LB, Rocha Pereira N, Figueiredo C, et al. Nocardia-induced granulocyte macrophage colony-stimulating factor is neutralized by autoantibodies in disseminated/extrapulmonary nocardiosis. Clin Infect Dis. 2015;60(7):1017-1025. doi:10.1093/cid/ciu968

19. Blackmon KN, Ravenel JG, Gomez JM, Ciolino J, Wray DW. Pulmonary nocardiosis: computed tomography features at diagnosis. $J$ Thorac Imaging. 2011;26(3):224-229. doi:10.1097/RTI.0b013 e3181f45dd5

20. Anagnostou T, Arvanitis M, Kourkoumpetis TK, Desalermos A, Carneiro HA, Mylonakis E. Nocardiosis of the central nervous system: experience from a general hospital and review of 84 cases from the literature. Medicine (Baltimore). 2014;93(1):19-32. doi:10.1097/ MD.0000000000000012

21. Chaussade H, Lebeaux D, Gras G, et al. Nocardia arthritis: 3 cases and literature review. Medicine (Baltimore). 2015;94(42):e1671. doi:10.1097/MD.0000000000001671
22. Playe M, Einfalt M, Toch SR, Froissart A, Bodardel G. 18F-FDG imaging of a case of disseminated nocardiosis. Clin Nucl Med. 2020;45(1):55-56. doi:10.1097/RLU.0000000000002842

23. Gajdács M, Urbán E. The relevance of anaerobic bacteria in brain abscesses: a ten-year retrospective analysis (2008-2017). Infect Dis. 2019;51(10):779-781. doi:10.1080/23744235.2019.1648857

24. Saubolle MA, Sussland D. Nocardiosis: review of clinical and laboratory experience. $J$ Clin Microbiol. 2003;41(10):4497-4501. doi:10.1128/JCM.41.10.4497-4501.2003

25. Gajdács M, Urbán E, Terhes G. Microbiological and clinical aspects of cervicofacial actinomyces infections: an overview. Dent J. 2019;7 (3):85. doi:10.3390/dj7030085

26. Rodriguez-Nava V, Lebeaux D, Lortholary O, Boiron P. Nocardia et nocardioses. Précis de Bactériologie Clinique. 3rd ed. ESKA/ LACASSAGNE; 2018:809-827.

27. Couble A, Rodriguez-Nava V, de Montclos MP, Boiron P, Laurent F. Direct detection of Nocardia spp. in clinical samples by a rapid molecular method. J Clin Microbiol. 2005;43(4):1921-1924. doi:10.1128/JCM.43.4.1921-1924.2005

28. Brown JM, Pham KN, McNeil MM, Lasker BA. Rapid identification of Nocardia farcinica clinical isolates by a PCR assay targeting a 314-base-pair species-specific DNA fragment. J Clin Microbiol. 2004;42(8):3655-3660. doi:10.1128/JCM.42.8.3655-3660.2004

29. Rouzaud C, Rodriguez-Nava V, Catherinot E, et al. Clinical assessment of a Nocardia PCR-based assay for diagnosis of nocardiosis. $J$ Clin Microbiol. 2018;56(6). doi:10.1128/JCM.00002-18

30. Coussement J, Lebeaux D, El Bizri N, et al. Nocardia polymerase chain reaction (PCR)-based assay performed on bronchoalveolar lavage fluid after lung transplantation: a prospective pilot study. PLoS One. 2019;14(2):e211989. doi:10.1371/journal.pone. 0211989

31. Conville PS, Brown-Elliott BA, Smith T, Zelazny AM. The complexities of Nocardia taxonomy and identification. J Clin Microbiol. 2018;56(1).

32. Conville PS, Zelazny AM, Witebsky FG. Analysis of $\sec A 1$ gene sequences for identification of Nocardia species. J Clin Microbiol. 2006;44(8):2760-2766. doi:10.1128/JCM.00155-06

33. Rodriguez-Nava V, Couble A, Devulder G, Flandrois JP, Boiron P, Laurent F. Use of PCR-restriction enzyme pattern analysis and sequencing database for hsp65 gene-based identification of Nocardia species. J Clin Microbiol. 2006;44(2):536-546. doi:10.1128/JCM.44.2.536-546.2006

34. Sánchez-Herrera K, Sandoval H, Mouniee D, et al. Molecular identification of Nocardia species using the $\operatorname{sodA}$ gene: identificación molecular de especies de Nocardia utilizando el gen sodA. New Microbes New Infect. 2017;19:96-116. doi:10.1016/j.nmni.2017.03.008

35. Kong F, Wang H, Zhang E, et al. secAl gene sequence polymorphisms for species identification of Nocardia species and recognition of intraspecies genetic diversity. J Clin Microbiol. 2010;48(11):39283934. doi:10.1128/JCM.01113-10

36. McTaggart LR, Richardson SE, Witkowska M, Zhang SX. Phylogeny and identification of Nocardia species on the basis of multilocus sequence analysis. J Clin Microbiol. 2010;48(12):4525-4533. doi:10.1128/JCM.00883-10

37. Tamura T, Ohji S, Ichikawa N, et al. Reclassification of Nocardia species based on whole genome sequence and associated phenotypic data. J Antibiot (Tokyo). 2018;71(7):633-641. doi:10.1038/s41429018-0043-1

38. Vautrin F, Bergeron E, Dubost A, et al. Genome sequences of three Nocardia cyriacigeorgica strains and one nocardia asteroides strain. Microbiol Resour Announc. 2019;8(33). doi:10.1128/ MRA.00600-19

39. Euzeby JP. List of bacterial names with standing in nomenclature: a folder available on the internet. Int J Syst Evol Microbiol. 1997;47 (2):590-592. doi:10.1099/00207713-47-2-590 
40. Blosser SJ, Drake SK, Andrasko JL, et al. Multicenter matrix-assisted laser desorption ionization-time of flight mass spectrometry study for identification of clinically relevant Nocardia spp. J Clin Microbiol. 2016;54(5):1251-1258. doi:10.1128/JCM.02942-15

41. Body BA, Beard MA, Slechta ES, et al. Evaluation of the Vitek MS v3.0 matrix-assisted laser desorption Ionization-time of flight mass spectrometry system for identification of mycobacterium and Nocardia species. J Clin Microbiol. 2018;56(6):e00237-18. doi:10.1128/JCM.00237-18

42. Girard V, Mailler S, Polsinelli S, et al. Routine identification of Nocardia species by MALDI-TOF mass spectrometry. Diagn Microbiol Infect Dis. 2017;87(1):7-10. doi:10.1016/j.diagmicrobio.2016.09.024

43. Durand T, Vautrin F, Bergeron E, et al. Assessment of VITEK $^{\circledR}$ MS IVD database V3.0 for identification of Nocardia spp. using two culture media and comparing direct smear and protein extraction procedures. Eur J Clin Microbiol Infect Dis. 2020;39(3):559-567. doi:10.1007/s10096-019-03758-x

44. McTaggart LR, Chen Y, Poopalarajah R, Kus JV. Incubation time and culture media impact success of identification of Nocardia spp. by MALDI-ToF mass spectrometry. Diagn Microbiol Infect Dis. 2018;92(4):270-274. doi:10.1016/j.diagmicrobio.2018.06.016

45. McTaggart LR, Doucet J, Witkowska M, Richardson SE. Antimicrobial susceptibility among clinical Nocardia species identified by multilocus sequence analysis. Antimicrob Agents Chemother. 2015;59(1):269-275. doi:10.1128/AAC.02770-14

46. CLSI. Performance Standards for Susceptibility Testing of Mycobacteria, Nocardia Spp. and Other Aerobic Actinomycetes. 1st ed. CSLSI supplement M62. Wayne, PA: Clinical and Laboratory Standards Institute; 2018.

47. Conville PS, Brown-Elliott BA, Wallace RJ, et al. Multisite reproducibility of the broth microdilution method for susceptibility testing of Nocardia species. J Clin Microbiol. 2012;50(4):1270-1280. doi:10.1128/JCM.00994-11

48. Valdezate S, Garrido N, Carrasco G, et al. Epidemiology and susceptibility to antimicrobial agents of the main Nocardia species in Spain. J Antimicrob Chemother. 2017;72(3):754-761.

49. Schlaberg R, Fisher MA, Hanson KE. Susceptibility profiles of Nocardia isolates based on current taxonomy. Antimicrob Agents Chemother. 2014;58(2):795-800. doi:10.1128/AAC.01531-13

50. Gombert ME, Aulicino TM. Synergism of imipenem and amikacin in combination with other antibiotics against Nocardia asteroides. Antimicrob Agents Chemother. 1983;24(5):810-811. doi:10.1128/ AAC.24.5.810

51. Gombert ME, Aulicino TM, duBouchet L, Silverman GE, Sheinbaum WM. Therapy of experimental cerebral nocardiosis with imipenem, amikacin, trimethoprim-sulfamethoxazole, and minocycline. Antimicrob Agents Chemother. 1986;30(2):270-273. doi:10.1128/ AAC.30.2.270

52. Gombert ME, Berkowitz LB, Aulicino TM, duBouchet L. Therapy of pulmonary nocardiosis in immunocompromised mice. Antimicrob Agents Chemother. 1990;34(9):1766-1768.

53. Lebeaux D, Freund R, van Delden C, et al. Outcome and treatment of nocardiosis after solid organ transplantation: new insights from a European study. Clin Infect Dis. 2017;64(10):1396-1405. doi:10.1093/cid/cix124

54. Nau R, Sörgel F, Eiffert H. Penetration of drugs through the bloodcerebrospinal fluid/blood-brain barrier for treatment of central nervous system infections. Clin Microbiol Rev. 2010;23(4):858-883. doi:10.1128/CMR.00007-10
55. Brown-Elliott BA, Biehle J, Conville PS, et al. Sulfonamide resistance in isolates of Nocardia spp. from a US multicenter survey. $J$ Clin Microbiol. 2012;50(3):670-672. doi:10.1128/JCM.06243-11

56. Ercibengoa M, Càmara J, Tubau F, et al. A multicentre analysis of Nocardia pneumonia in Spain: 2010-2016. Int J Infect Dis. 2020;90:161-166. doi:10.1016/j.ijid.2019.10.032

57. Conan PL, Matignon M, Bleibtreu A, et al. Traitement par monothérapie de cotrimoxazole des nocardioses chez les patients transplantés d'organe solide: résultats d'une étude européenne multicentrique rétrospective. Med Mal Infect. 2019;49(4):S76. doi:10.1016/j.medmal.2019.04.182

58. Davidson N, Grigg MJ, McGuinness SL, Baird RJ, Anstey NM. Safety and outcomes of linezolid use for nocardiosis. Open Forum Infect Dis. 2020;7(4):ofaa090. doi:10.1093/ofid/ofaa090

59. Shen T, Wu L, Geng L, Wei Z, Zheng S. Successful treatment of pulmonary Nocardia farcinica infection with linezolid: case report and literature review. Braz J Infect Dis. 2011;15(5):486-489.

60. Tripodi MF, Durante-Mangoni E, Fortunato R, et al. In vitro activity of multiple antibiotic combinations against Nocardia: relationship with a short-term treatment strategy in heart transplant recipients with pulmonary nocardiosis. Transpl Infect Dis. 2011;13(4):335343. doi:10.1111/j.1399-3062.2010.00588.x

61. MacGowan AP. Pharmacokinetic and pharmacodynamic profile of linezolid in healthy volunteers and patients with Gram-positive infections. $J$ Antimicrob Chemother. 2003;51(Suppl 2):ii17-25. doi:10.1093/jac/dkg248

62. Restrepo A, Clark NM. Nocardia infections in solid organ transplantation: guidelines from the infectious diseases community of practice of the American society of transplantation. Clin Transplant. 2019;33 (9):e13509. doi:10.1111/ctr.13509

63. Wallace RJ, Septimus EJ, Williams TW, et al. Use of trimethoprimsulfamethoxazole for treatment of infections due to Nocardia. Rev Infect Dis. 1982;4(2):315-325. doi:10.1093/clinids/4.2.315

64. Mootsikapun P, Intarapoka B, Liawnoraset W. Nocardiosis in Srinagarind Hospital, Thailand: review of 70 cases from 1996-2001. Int J Infect Dis. 2005;9(3):154-158. doi:10.1016/j.ijid.2004.06.011

65. Soman R, Koparkar V, Almeida A, Shetty A, Rodrigues C. Paradoxical response in cerebral nocardiosis in a renal transplant recipient. J Assoc Physicians India. 2018;66(9):91-92.

66. Douglas AP, Thursky KA, Worth LJ, et al. FDG PET/CT imaging in detecting and guiding management of invasive fungal infections: a retrospective comparison to conventional CT imaging. Eur J Nucl Med Mol Imaging. 2019;46(1):166-173. doi:10.1007/s00259-018-4062-8

67. Brown-Elliott BA, Killingley J, Vasireddy S, Bridge L, Wallace RJ. In vitro comparison of ertapenem, meropenem, and imipenem against isolates of rapidly growing mycobacteria and Nocardia by use of broth microdilution and etest. J Clin Microbiol. 2016;54(6):15861592. doi:10.1128/JCM.00298-16

68. Gomez-Flores A, Welsh O, Said-Fernandez S, Lozano-Garza G, TavarezAlejandro RE, Vera-Cabrera L. In vitro and in vivo activities of antimicrobials against Nocardia brasiliensis. Antimicrob Agents Chemother. 2004;48 (3):832-837. doi:10.1128/AAC.48.3.832-837.2004

69. Hamdi AM, Fida M, Deml SM, Abu Saleh OM, Wengenack NL. Retrospective analysis of antimicrobial susceptibility profiles of Nocardia species from a tertiary hospital and reference laboratory, 2011 to 2017. Antimicrob Agents Chemother. 2020;64(3).

70. Rouzaud C, Mainardi JL, Lortholary O, Lebeaux D. Traitement des nocardioses: plus de questions que de réponses? Jl des Anti-infectieux. 2014;16:175-184. doi:10.1016/j.antinf.2014.10.001 


\section{Publish your work in this journal}

Infection and Drug Resistance is an international, peer-reviewed openaccess journal that focuses on the optimal treatment of infection (bacterial, fungal and viral) and the development and institution of preventive strategies to minimize the development and spread of resistance. The journal is specifically concerned with the epidemiology of

Submit your manuscript here: https://www.dovepress.com/infection-and-drug-resistance-journa| antibiotic resistance and the mechanisms of resistance development and diffusion in both hospitals and the community. The manuscript management system is completely online and includes a very quick and fair peerreview system, which is all easy to use. Visit http://www.dovepress.com/ testimonials.php to read real quotes from published authors. 